\title{
O paradigma multiculturalista e o protagonismo etnopolítico das comunidades indígenas: Um olhar Geográfico Contemporâneo e crítico sobre a questão
}

The multiculturalist paradigm and the ethnopolitical protagonism of indigenous communities: a contemporary and critical geographical perspective of the issue

El paradigma multiculturalista y el protagonismo etnopolítico de las comunidades indígenas: Una visión geográfica contemporánea y crítica sobre el tema

José Dias Neto ${ }^{1}$ https://orcid.org/0000-0002-4639-3335

José Antônio Souza de Deus ${ }^{2}$ https://orcid.org/0000-0002-1737-4960

\footnotetext{
${ }^{1}$ Instituto de Geociências da Universidade Federal de Minas Gerais- UFMG, Belo Horizonte- Minas Gerais Brasil, josedineto@yahoo.com.br.

${ }^{2}$ Universidade Federal de Minas Gerais/ Programa de Pós-Graduação em Geografia - UFMG, Belo Horizonte- Minas Gerais Brasil, email: jantoniosdeus@uol.com.br.
}

\section{Resumo}

Este artigo tem por objetivo estabelecer uma reflexão a respeito da influência da emergência do paradigma multiculturalista no observado protagonismo etnopolítico das comunidades indígenas na contemporaneidade. Para tanto, apresenta uma análise bibliográfica acerca dos conceitos de pluralismo étnico, multiculturalismo, novo ambientalismo e socioambientalismo que, numa perspectiva histórica, contribuíram para a formatação de um contexto favorável para atuação dos movimentos étnicos, dentre os quais se destacam os relacionados aos povos indígenas, o que serviu, em contrapartida, para estimular e impulsionar os estudos culturais no âmbito da Geografia.

Palavras-chave: Multiculturalismo, protagonismo etnopolítico, comunidades indígenas.

\begin{abstract}
This paper aims to establish a reflection on the influence of the emergence of the multiculturalist paradigm on the observed ethnopolitical role of indigenous communities in contemporary times. To this, it presents a bibliographic analysis about the concepts of ethnic
\end{abstract}


pluralism, multiculturalism, new environmentalism and socio-environmentalism that, in a historical perspective, contributed to the formation of a favorable context for the performance of ethnic movements, among which those related to indigenous peoples stand out, which, on the other hand, served to stimulate and boost cultural studies within the scope of Geography.

Keywords: Multiculturalism, ethnopolitical protagonism, indigenous communities.

\section{Resumen}

Este artículo tiene como objetivo establecer una reflexión sobre la influencia del surgimiento del paradigma multiculturalista sobre el papel etnopolítico observado de las comunidades indígenas en los tiempos contemporáneos. Para ello, presenta un análisis bibliográfico sobre los conceptos de pluralismo étnico, multiculturalismo, nuevo ambientalismo y socioambientalismo que, desde una perspectiva histórica, contribuyeron a la formación de un contexto favorable para el desempeño de los movimientos étnicos, entre los que destacan los relacionados con los pueblos indígenas. , que, por otro lado, sirvió para estimular e impulsar los estudios culturales en el ámbito de la Geografía.

Palabras clave: Multiculturalismo. Protagonismo etnopolítico. Comunidades indígenas.

\section{Introdução}

Este artigo tem como propósito refletir sobre a influência do paradigma multiculturalista na composição de um contexto favorável à emergência do protagonismo das comunidades indígenas observado na contemporaneidade, conforme defendido por Deus et al. (2012), Costa (2016) e Dias Neto (2019), através da tentativa de aproximação das (profundas e acaloradas) discussões teóricas e conceituais apresentadas no âmbito da academia, sobretudo no campo das Ciências Humanas, com destaque para a Geografia, ao contexto político que se desenhava no cenário nacional e internacional a partir da segunda metade do século XX.

A importância atribuída às questões ambientais e as abordagens científicas e acadêmicas incidentes desse período constituíram uma resposta a uma conjuntura social, política e ambiental específicas (ACSELRAD, 2004), o que quer dizer que o ponto de inflexão para a reavaliação epistêmica no âmbito acadêmico teve um caráter 
DEUS, J. A. S.; DIAS NETO, J.

externo, tendo partido de um movimento heterônomo e surgido como resultado de um fenômeno que rompeu com as estruturas então vigentes e que desafiou sociedade, governos, agentes privados e atores internacionais: o novo ambientalismo. Vale ressaltar que o processo social de construção da "crise ambiental", segundo Acselrad (2004), é algo vinculado às dinâmicas da sociedade e da cultura e, sendo assim, para compreender esse fenômeno é necessário um olhar ampliado e holístico sobre os aspectos socioculturais, políticos, econômicos e ambientais e acerca da forma como foram apropriados nas diferentes esferas da vida pelos distintos atores com os quais estiveram envolvidos.

A Geografia, segundo Amorim Filho (1999), colocou-se na vanguarda das reflexões estabelecidas nesse sentido, contribuindo com o seu aprofundamento/esclarecimento através de uma dinâmica que ressignificou a própria ciência geográfica. De forma paralela, a sociedade seguia seu curso e novas respostas eram construídas para dar conta dos complexos dilemas ambientais que surgiam. Movimentos sociais ganharam fôlego, as minorias culturais e étnicas passaram a ser ouvidas, as relações entre os atores sociais se redesenhava e novos desafios emergiam em todas as áreas.

\section{Da emergência do pluralismo cultural ao multiculturalismo: a composição de uma} agenda cultural

O novo ambientalismo, derivado da tomada de consciência acerca das novas formas de relacionamento entre os homens e seu meio ambiente, foi (e continua sendo) um movimento que trouxe as questões ecológicas para o centro dos debates contemporâneos e contribuiu para a reorientação das Ciências Humanas (AMORIM FILHO, 1999), não se restringindo a influenciar apenas o campo científico. Os reflexos deste processo sobre a política e a economia, traduzidos na emergência dos paradigmas da "sustentabilidade" e do "desenvolvimento sustentável", provenientes da configuração de uma rede global (exemplificada pelo Clube de Roma em 1968 e a Conferência de Estocolmo em 1972) para debater e buscar contornar, no campo 
DEUS, J. A. S.; DIAS NETO, J.

político e econômico, a crise ambiental que passava a atormentar ${ }^{3}$ e desafiar a humanidade no século XX, são fatores que contribuíram para a virada de chave ao multiculturalismo (D'ADESKY, 1997). A vitória simbólica do liberalismo sobre o comunismo decretada com a queda do Muro de Berlim em 1989 e a derrocada da União Soviética a partir da decadência do Partido Comunista Soviético apresentou um paradoxo ao modelo político-econômico que viria a se tornar hegemônico deste então: a corrida capitalista rumo ao desenvolvimento versus a difusão dos valores democráticos ao redor do mundo por intermédio da propagação dos american way of life e da globalização.

O discurso da inclusão e da participação passaram a ser então fortemente difundidos, estimulados também pela emergência do movimento ambientalista que influenciava a agenda internacional (principalmente nos fronts social e ambiental) pósGuerra Fria e forçava os Estados Nação a voltarem o olhar, mesmo que coercitivamente, para a composição étnica e cultural dos seus povos. Diversas convenções internacionais relacionadas à questão cultural passaram a ser organizadas e implementadas, como a Convenção da Organização Internacional do Trabalho (OIT) 1694, publicada pela ONU em 1989 e ratificada pelo Brasil em 2002, que trata da participação de povos indígenas e tribais no processo de instalação de empreendimentos que pudessem exercer algum tipo de influência sobre os seus territórios, passando a pressionar a comunidade internacional a não mais negligenciar, ou submeter a um segundo plano, sua diversidade cultural e étnica. Como consequência dessa pressão observamos, pelo menos no plano do discurso oficial, a busca pelo reconhecimento do pluralismo étnico por parte dos países, embora esse reconhecimento não tenha se refletido em políticas afirmativas e mais inclusivas no

\footnotetext{
${ }^{3}$ Ideia que pode ser defendida com base nos inúmeros acidentes ambientais ocorridos no século XX, como a "névoa do Vale do Meuse", na Bélgica, em 1930; o acidente de Donodora, em 1948; a "névoa matadora de Londres", de 1952; a "doença dos gatos dançantes" da Bacia de Minamata, no Japão, em 1956; e a tragédia do Love Canal, todos retratados por Hogan (1989) como incidentes ambientais de significativa relevância e magnitude para a humanidade, motivando a reavaliação das formas de se relacionar com o meio ambiente pelo homem.

${ }^{4}$ Segundo o ISA, a Convenção OIT 169 tem sido atualmente apropriada "como instrumento de enfrentamento às violações aos direitos dos povos e comunidades tradicionais.” (ISA, 2017).
}

Geopauta, Vitória da Conquista; ISSN: 2594-5033, V. 5, n.1, 2021, e6504 
DEUS, J. A. S.; DIAS NETO, J.

que se refere à diversidade cultural e étnica, aspecto tratado por D’adesky (1997) ao abordar as diferenças entre o pluralismo e o multiculturalismo.

Por essa razão, o reconhecimento político do pluralismo cultural, em grande medida forçado, fruto de pressões da sociedade internacional no âmbito dos movimentos ambientais e da rede de cooperação internacional entre os países, não encerrou os conflitos inerentes a esse campo, conforme assinalado por Deus et al. (2009), que passaram a ser encarados sob a perspectiva do novo ambientalismo emergente, no qual se destaca o processo de globalização das agendas socioambientais no âmbito dos Estados nacionais. Na realidade, conforme Deus et al. (2009) registram, as discussões culturais emergentes lançaram uma nova luz sobre o assunto e contribuíram para a revalorização e revitalização de seus temas e conceitos, em que se destacam:

O papel das clivagens intercivilizacionais como chave de interpretação para os conflitos atuais, o redesenho das religiões no mundo, a emergência de identidades coletivas, a formação e diferenciação de paisagens culturais alternativas, a ressignificação dos movimentos migratórios, a legitimação do ordenamento como instrumento de intervenção do Estado no território, a gestação/ afirmação de uma geopolítica da biodiversidade imbricada com processos de etnodesenvolvimento e etnossustentabilidade resgatando saberes de comunidades tradicionais (que se reterritorializam), etc. (DEUS et al, 2009, p. 65).

O recrudescimento das questões culturais passou, portanto, por uma conjuntura favorável à sua ressignificação. E, embora este se trate de um processo gestado no âmbito da globalização, ele pode ser entendido, contudo, a partir de aspectos que lhes são específicos como, por exemplo, a sua derivação do novo ambientalismo que, inclusive, estimulou os atores globais a tratarem da temática, dinâmica que impeliu os Estados, pelo menos na via do discurso formal, a reconhecer o pluralismo cultural como um valor, haja vista que não fazê-lo significaria caminhar na contramão do movimento socioambientalista emergente e seus valores a respeito do "desenvolvimento sustentável" que, no âmbito internacional, ganhava forma e passaria, alguns anos mais tarde, a pressionar a chamada sociedade global em torno 
DEUS, J. A. S.; DIAS NETO, J.

da adoção de uma agenda social e ambiental comum, por exemplo, através da Agenda $21^{5}$ e dos Objetivos de Desenvolvimento do Milênio ${ }^{6}$ (que mais tarde se tornariam os Objetivos de Desenvolvimento Sustentável).

Deste modo, ainda que possa (e deva ser) relativizado, o reconhecimento do pluralismo cultural, embora não tenha trazido mudanças significativas no que diz respeito às políticas públicas e ao exercício da cidadania, trouxe condições favoráveis aos grupos étnicos para reivindicarem condições de igualdade e valor intrínseco às diferentes culturas num dado território geográfico, conforme apontado por D’adesky (1997). Embora esse reconhecimento, em um primeiro momento, não tenha necessariamente significado o estabelecimento de uma política voltada à questão cultural, ele lançou as bases que seriam apropriadas pelas culturas emergentes e se desencadeariam no multiculturalismo, este sim, um processo de conotação política e que pressupõe a atuação do Estado para valorização e preservação da diversidade étnica e cultural - embora esta seja uma abordagem kantiana do multiculturalismo que será, mais adiante, questionada pela perspectiva comunitarista. Assim, pluralismo e multiculturalismo se diferenciam, sendo o primeiro anterior e uma condição para que o segundo aconteça. A autora busca deixar clara essa diferenciação ao apontar que:

O pleno reconhecimento da igualdade e da cidadania, associado a questão de igualdade e tratamento às culturas de grupos étnicos diferentes, aponta precisamente na direção de uma política multicultural, e não na do pluralismo cultural tal como expresso na Constituição [de 1998]. É justamente nesse ponto que se diferenciam as duas perspectivas. Pois o pluralismo cultural não abarca necessariamente a política de tratamento em pé de igualdade das

\footnotetext{
${ }^{5}$ A Agenda 21 Global foi construída com a participação de governos e instituições da sociedade civil de 179 países, em um processo que durou dois anos e culminou com a realização da Conferência das Nações Unidas sobre Meio Ambiente e Desenvolvimento (CNUMAD), no Rio de Janeiro, em 1992, também conhecida por Rio'92. O programa de implementação da Agenda 21 e os compromissos para com a carta de princípios do Rio foram fortemente reafirmados durante a Cúpula de Johannesburgo, ou Rio + 10, em 2002.

(Fonte: http://www.institutoatkwhh.org.br/compendio/?q=node/21 Acesso em 27 de novembro de 2018)

${ }^{6}$ As metas do milênio, correspondentes a uma agenda internacional para o desenvolvimento social e econômico dos países, foram estabelecidas pela Organização das Nações Unidas (ONU) em 2000, com o apoio de 191 nações, e ficaram conhecidas como Objetivos de Desenvolvimento do Milênio (ODM). São eles: 1 - Acabar com a fome e a miséria; 2 - Oferecer educação básica de qualidade para todos; 3 - Promover a igualdade entre os sexos e a autonomia das mulheres; 4 - Reduzir a mortalidade infantil; 5 - Melhorar a saúde das gestantes; 6 - Combater a Aids, a malária e outras doenças; 7 - Garantir qualidade de vida e respeito ao meio ambiente; 8 - Estabelecer parcerias para o desenvolvimento. A vigência dos ODM foi até o ano de 2015, quando a ONU reformulou a agenda para o desenvolvimento ao lançar os Objetivos de Desenvolvimento Sustentável (ODS), que serão vigente entre 2015-2030.

(Fonte: http://www.odmbrasil.gov.br/os-objetivos-de-desenvolvimento-do-milenio Acesso em 27 de novembro de 2018).
}

Geopauta, Vitória da Conquista; ISSN: 2594-5033, V. 5, n.1, 2021, e6504 
DEUS, J. A. S.; DIAS NETO, J.

diferentes culturas que se encontram num dado território geográfico. Ao contrário, o multiculturalismo tende necessariamente a reconhecer a igualdade de valor intrínseco de cada cultura. É importante diferenciar bem essas duas perspectivas (D'ADESKY, 1997, p. 173).

Portanto, sublinha-se que o multiculturalismo pode ser entendido como um processo de forte conotação política no qual a diversidade cultural passa a ser pensada sob uma perspectiva positiva, e não mais neutra, como no pluriculturalismo, buscando assegurar aos diferentes grupos culturais condições simétricas à manutenção/preservação de seus modos de vida, garantindo-lhes condições legais para sua inclusão/participação política, elementos não pensados em momentos anteriores. Esse caráter político do multiculturalismo aproxima os grupos étnicos dos direitos políticos e humanos, colocando em destaque o debate sobre o exercício da cidadania e a soberania dos povos tradicionais, de onde deriva a consciência sobre a necessidade de que lhes seja assegurada a preservação e manutenção dos seus modos de vida, territórios, identidades, cosmovisão e valores.

Segundo D’adesky (1997), o caráter político do multiculturalismo estaria relacionado ao reconhecimento da igualdade de valor intrínseco à cada cultura ante a legislação do seu país, através da adoção/implementação de políticas públicas e/ou mecanismos que favoreçam sua participação/integração à sociedade nacional, vinculadas aos princípios democráticos - vale destacar que a correlação entre multiculturalismo e as teorias da cidadania e da democracia são apontadas também por Torres (2001). O trecho seguinte clarifica o entendimento sobre o caráter político intrínseco ao multiculturalismo, no sentido da reivindicação do reconhecimento explícito e adequado da etnia.

O reconhecimento explícito e adequado da etnia representaria, para aqueles que defendem o respeito às diferenças étnicas, o resultado de uma exigência existencial fundamental, na medida em que consideram que o desejo de reconhecimento deve realizar-se tanto em nível individual quanto coletivo. Para eles, o simples reconhecimento da igualdade individual é insuficiente sem o reconhecimento simultâneo e adequado do valor das particularidades étnicas. Alegam que não

Geopauta, Vitória da Conquista; ISSN: 2594-5033, V. 5, n.1, 2021, e6504 
podem abrir mão dos dois níveis de reconhecimento, pois sustentam que o Estado brasileiro, ao representar os interesses da etnia dominante, reconhece de fato o valor e a primazia desta última sobre as outras. (D'ADESKY, 1997, p. 167).

Nessa mesma direção, Oliveira (2006) também destaca o caráter político do multiculturalismo e sua aproximação aos preceitos da democracia ao afirmar que:

Pode-se observar nos diversos cenários uma expectativa dos agentes sociais, étnicos ou nacionais, quanto à elevação daquilo que poderíamos chamar de 'taxa de consideração'. É importante se ter em conta que, enquanto os dois primeiros pontos são de ordem política em que políticas públicas como a 'ação afirmativa' ou o multiculturalismo, entre outras, teriam uma demanda certa (...) (OLIVEIRA, 2006, p. 112).

O que se observa é que o paradigma multiculturalista está relacionado à garantia das condições de existência, e aqui poderia ser incluída também a ideia de sobrevivência, dos grupos étnicos, e que esse aspecto está relacionado ao reconhecimento e incorporação do multiculturalismo pelas forças políticas estatais, através da formulação e aplicação de legislações e políticas públicas afirmativas de discriminação positiva, conforme sugerido por Oliveira (2006). Segundo Basso (2015), a discussão sobre o multiculturalismo deve basear-se na compreensão da:

Postura ativa estatal no sentido de promover políticas multiculturais, que empreendam o reconhecimento dos direitos dos diferentes grupos étnicos (inclusos nesses os ditos "indígenas") e concedendo meios para que esses direitos sejam realmente exercitados - e não apenas formalmente reconhecidos (BASSO, 2015, p. 118).

Deste modo, o multiculturalismo contemporâneo ao reconhecer e legitimar a importância dos grupos étnicos, por conseguinte, lhes proporciona a possibilidade de exercício de maior protagonismo no que diz respeito aos assuntos do seu interesse como, por exemplo, na ocasião de processos de licenciamento ambiental que impactem de forma direta ou indireta as populações tradicionais situadas nas proximidades do empreendimento pretendido, pela adoção de mecanismos pelos quais a legislação torna obrigatória a participação de tais comunidades, como é possível se observar no 
DEUS, J. A. S.; DIAS NETO, J.

Decreto Federal 5.051, de 19 de abril de 2004, que tem por finalidade implementar a nível nacional, a Convenção 169 da Organização Internacional do Trabalho (OIT), da ONU, que versa sobre os direitos dos povos indígenas e tribais e que comporia a chamada "taxa de consideração" proposta por Oliveira (2006).

No Brasil, a Constituição Federal de 1988, decorrente do processo de redemocratização do país, passou a oficialmente reconhecer a dignidade universal da pessoa humana garantindo, pelo menos em seu discurso oficial, a liberdade e a igualdade dos cidadãos independentemente de sexo, raça, religião e etnia, passando a levar em conta a diversidade étnica e o pluralismo cultural (D’ADESKY, 1997).

Ressalta-se que a ampliação dos direitos universais iluminou as reflexões sobre o direito das minorias, uma vez que é no reconhecimento de que todos são iguais que se engendram as diferenças, ou seja, a igualdade política de todos os grupos étnicos em um território, a qual, por sua vez, está embasada no princípio da garantia da dignidade humana que fundamenta o direito contemporâneo (GOMES, 2010), proporcionando que as especificidades culturais se aflorem, manifestem e passem a reivindicar, justamente, a igualdade legalmente prometida. Por essa razão, comunidades indígenas quando chamadas a participar dos processos de planejamento territorial e licenciamento ambiental, por exemplo, colocam em pauta as especificidades culturais que lhes são inerentes, através da formulação de um discurso que, retoricamente, enfatiza a diferença embasando-se na igualdade. A esse respeito, Basso (2015) afirma que:

Há uma forte tensão entre a concepção universalista dos direitos humanos, lastreada nas bases de valores como a liberdade e a igualdade, e, de outro lado, uma concepção particularista da sociedade, fundada em um "direito à diferença", em políticas de reconhecimento e de alteridade. $\mathrm{O}$ sistema universalista dos direitos humanos, nascido com a Carta da Organização das Nações Unidas (ONU), de 1945, e a Declaração Universal dos Direitos Humanos, de 1948, prega que "todas as pessoas nascem livres e iguais em dignidade e direitos" (Artigo I, da Declaração - com destaques do autor). Os horrores da Segunda Guerra Mundial e as injustiças cometidas pelo nacional-socialismo alemão para com certas minorias levaram a um

Geopauta, Vitória da Conquista; ISSN: 2594-5033, V. 5, n.1, 2021, e6504 
consenso mundial a respeito da necessidade de se reconhecerem certos direitos que seriam atribuíveis a toda e qualquer pessoa, de forma universal, equitativa e livre, fundando-se, assim, em um ideal liberal de direitos humanos. (...) Com a queda do muro de Berlim e o fim da Guerra Fria, conflitos multiculturais surgiram na Europa oriental, como a guerra civil na Bósnia-Herzegovina e a destruição russa da Chechênia, bem como em outros pontos do mundo, como os conflitos nacionais no Azerbaijão, Armênia, Macedônia, a ascensão dos fundamentalistas islâmicos na Argélia, no norte da África e no Oriente Médio (BENHABIB, 1996, p. 3), assim como na América Latina a tensão entre os grupos indígenas e os não-índios aumentava, com o crescente reconhecimento de direitos dos primeiros (COTT, 2006, p. 272-3). Com a ascensão desses conflitos, também aumentou o reconhecimento de "políticas da diferença", em detrimento das concepções universalistas que até então reinavam, desde a Declaração Universal de 1948 (BASSO, 2015, p. 114-115).

De acordo com Oliveira (2006), em uma perspectiva crítica sobre os resultados práticos do multiculturalismo, a "taxa de consideração" é o corolário ético decorrente da dinâmica de reconhecimento da identidade étnica e do respeito à diferença, que reflete-se na expectativa por parte de agentes sociais, étnicos ou nacionais quanto à sua elevação, de onde podemos observar o seu caráter instrumental/pragmático.

Ademais, importa destacar também o fenômeno da globalização, que guarda vínculos com o novo ambientalismo, bem como com o movimento do pluralismo ao multiculturalismo, uma vez que as novas formas de encarar a relação entre o homem e o meio ambiente contribuíram, pelo menos em tese, para a formação de uma rede global de cooperação/preservação ambiental e que, conforme Ioris (2007), pode ser entendido como um dos fatores motivadores para a emergência do paradigma multiculturalista a partir da ideia de sociedade global (TORRES, 2001; IORIS, 2007). Já de acordo com Cogo (2001), o reconhecimento do multiculturalismo contemporâneo é uma espécie de passaporte para a sociedade global. Isso porque pensar uma comunidade global, ou seja, pensar a totalidade do nosso planeta, consequentemente, nos condicionaria a refletir sobre as partes que seriam necessárias para sua composição. 
DEUS, J. A. S.; DIAS NETO, J.

Essa reflexão, no campo ambiental, correlaciona-se à segunda metade do século $X X$, que é reconhecidamente um período de efervescência cultural. Movimentos populares emblemáticos impulsionados pelo debate ambiental surgiram então, como os hippies, promovendo reflexões sobre formas alternativas de vida. Além disso, o movimento ambientalista também ganhou força, à época, com o surgimento de instituições como o World Wide Fund for Nature (WWF), o Green Peace e o Instituto Socioambiental (ISA), de caráter conservacionista e que, além das questões propriamente ambientais, ocupam-se também de pautas sociais e culturais. Assim, aos processos de desenvolvimento econômico passou a ser acoplada uma agenda ambiental que, além da preservação do meio ambiente, integrou também a preservação/manutenção das culturas. É a inflexão, a virada de chave ao “desenvolvimento sustentável".

É relevante assinalar ainda que o processo de composição de uma agenda ambiental global, ao proporcionar a reflexão acerca da importância das questões sociais e ambientais no mesmo patamar de relevância do que as econômicas, incorpora a diversidade cultural dos povos como variável relevante no processo de desenvolvimento. Isso fez com que os olhares do mundo se voltassem às comunidades tradicionais, com destaque para a diversidade étnica e racial brasileira, assim como destacado por Ribeiro (1996) ao retratar que a UNESCO, ao se voltar para o Brasil, viu aqui um grande depósito das riquezas culturais e ambientais do mundo.

Desta forma, este quadro contribuiu também para estimular o interesse do senso comum pelas questões culturais, com destaque para os povos indígenas, provocando no público geral um sentimento de relativa simpatia, proveniente, justamente, do princípio da dignidade humana e dos direitos universais, que ganha uma valoração positiva mediante a propagação dos valores humanos e democráticos, incorporando em seu discurso uma ideia de conservação/preservação inerente.

Além disso, esse contexto acaba por delinear uma conjuntura favorável ao desenvolvimento e propagação dos estudos culturais, tanto no âmbito da Geografia 
quanto de outras Ciências Humanas, motivados pelo interesse da sociedade global em conhecer, considerar e preservar as diversas formas culturais. $\mathrm{O}$ interesse pelo exótico que sempre se fez presente no discurso e nas análises antropológicas é, nesse contexto, incorporado pelo senso comum, muito em função da propagação do universalismo dos direitos humanos e dos valores políticos democráticos pelos mass media, que passam a contemplar a identidade étnica e a cultura sob outra perspectiva, não mais a da classificação pejorativa decorrente do contraponto comtiano ${ }^{7}$ entre civilização e barbárie, baseado na ideia de que o pluralismo cultural é algo a ser superado; mas sim, da diversidade cultural como fator positivo de diferenciação dos povos e politicamente relacionada à ideia de direitos humanos, assim como apresentado por Gomes (2010).

\section{Protagonismo contemporâneo das comunidades indígenas: multiculturalismo e socioambientalismo como catalisadores do processo}

O protagonismo social e político das populações tradicionais, destacando-se, aí, as comunidades indígenas, vincula-se à emergência do novo ambientalismo que, por seu curso, pode ser pensado no contexto de valorização dos paradigmas do multiculturalismo e do socioambientalismo. Sem querer aqui ficar dispendendo tempo no tratamento de paradoxos desprovidos de sentido, como uma possível reflexão acerca do que tenha vindo primeiro, se o novo ambientalismo, o socioambientalismo ou o multiculturalismo, importa sublinhar que estas são estruturas conceituais e conjunturais que interpenetram-se e interdigitam-se e que, no final das contas, contribuem para a (des)organização da complexa sociedade contemporânea.

O multiculturalismo, como vimos, envolve a busca pela preservação de diferentes culturas ou identidades culturais, em uma sociedade unificada através do fenômeno da globalização, sob a égide do Estado. O socioambientalismo, decorrente

\footnotetext{
${ }^{7}$ Referente a Augusto Comte, autor que trabalha a ideia da evolução das sociedades por uma tríplice sequência de etapas: selvageria, barbárie e, finalmente, civilização. Essa foi, inclusive, a base ideológica do indigenismo brasileiro, conforme apontado por Oliveira (2006).
}

Geopauta, Vitória da Conquista; ISSN: 2594-5033, V. 5, n.1, 2021, e6504 
DEUS, J. A. S.; DIAS NETO, J.

das preocupações ambientais surgidas a partir das décadas de 60 e 70 do século passado, com ênfase para o movimento de luta por justiça ambiental constituído nos EUA formado, por sua vez, a partir de uma articulação entre movimentos sociais de caráter ambiental, social, territorial e de direitos civis (BULLARD, 2000), permitiu a emergência de um cenário que tem favorecido a mobilização e articulação dos povos tradicionais. Esses dois fatores, presume-se, integram o novo ambientalismo, que segundo Amorim Filho (1999), não corresponderia a uma estrutura conceitual ou teórica, mas, sim, a um período da história:

O período atual da história humana, que coincide com a passagem do milênio, testemunha vários fenômenos e processos relevantes para a humanidade. Entre eles, um dos mais significativos tem sido a difusão de uma nova maneira de encarar e valorizar o ambiente no qual vivemos (AMORIM FILHO, 1999, p. 139).

Assim, ao voltarmos o olhar para a formação histórica do mundo contemporâneo percebemos que, no mesmo intervalo, a partir da segunda metade do século $\mathrm{XX}$, de um lado o multiculturalismo estimulava e, até certo ponto, se apresentava como uma resposta à estrutura da política estatal relacionada à inclusão pragmática dos grupos étnicos na arena política (e não simplesmente o seu reconhecimento, como no pluralismo cultural); e do outro, o socioambientalismo surgia como um movimento de base, oriundo da própria sociedade através da emergência de uma nova agenda ambiental que reivindicava maior espaço às questões sociais em detrimento do caráter puramente econômico do desenvolvimento. Deste modo, em suas especificidades, o multiculturalismo agrega uma visão política e jurídica gestada no interior da organização estatal; já o socioambientalismo, como fruto de uma conjuntura social e econômica, incorpora nos processos de desenvolvimento no seio da sociedade capitalista a agenda da sustentabilidade; e não à toa, pesquisadores passaram a classificar esse processo como capitalismo verde (BARBIERI, 1998; DIAS; TOSTES, 2009; PAULA; MORAIS, 2013).

Desenha-se, então, um cenário de tensão no interior do Estado contemporâneo, haja vista se delinear, de forma clara, interesses antagônicos entre os atores que

Geopauta, Vitória da Conquista; ISSN: 2594-5033, V. 5, n.1, 2021, e6504 
DEUS, J. A. S.; DIAS NETO, J.

integram esse cenário (Estado, sociedade, setor privado, etc.), e as comunidades étnicas, passam a ser consideradas como parte integrante no jogo. Em contrapartida, o multiculturalismo favorece a articulação política em torno da questão cultural, por estar relacionado, indiretamente, à luta pelo direito das minorias, uma vez que possui como característica a adoção, nas esferas política e jurídica, por parte dos Estados, de mecanismos que possibilitam o reconhecimento e tratamento das diferenças culturais e étnicas no interior da sociedade (BASSO, 2015).

Mais adequado tratar o multiculturalismo sob a perspectiva de um projeto (SANTOS; NUNES, 2004, p. 5-6), em que o reconhecimento das diversidades culturais passa a compor as metas e políticas de um determinado Estado-nação, naquilo que Keith Banting e Will Kymlicka (2006, p. 1) denominam "políticas multiculturais" (BASSO, 2015, p. 118).

Ao considerar o multiculturalismo como um projeto, o autor pressupõe a ação inerente à sua elaboração, que se dá através da implementação de políticas multiculturais, abordadas no interior do Estado como uma forma de reconhecer a diversidade cultural dos grupos que o integram.

É sugestivo notar ainda que as políticas multiculturais, ao se ramificarem no interior da sociedade, compõem o quadro favorável para a emergência do protagonismo dos grupos étnicos, entre os quais destacamos, mais uma vez, os povos indígenas. E o front ambiental, impregnado pelas políticas multiculturais e marcado epistemologicamente pela elevação do paradigma do socioambientalismo, e também por sua interconectividade com o multiculturalismo, revela-se como uma das principais arenas nas quais a questão cultural passa a ser tratada, já que para o movimento socioambientalista, a inclusão e a participação são princípios estruturantes. Por isso, podemos observar quantidade considerável de processos de licenciamento ambiental de grandes projetos marcados por conflitos entre empresas e grupos étnicos, como é o caso da Usina Hidrelétrica Belo Monte e da Usina 
Hidrelétrica São Luiz do Tapajós, marcados pela incisiva e destacada atuação das comunidades indígenas e ribeirinhas impactadas por esses empreendimentos.

Deste modo, vemos que a partir do contexto multiculturalista, as questões étnicas e culturais ganham novos contornos, pois, emerge uma conjuntura que se lhes mostra favorável do ponto de vista da estrutura hegemônica de poder - embora não devamos perder de vista a criticidade para avaliar essa dinâmica, e na qual a diversidade étnica passa a ser tratada como um valor, inclusive pelos próprios grupos culturais em seus processos de autoafirmação e ressignificação, com base na valorização e resgate da diversidade étnica e cultural. E marcam-se, aí, novas territorialidades indígenas, observando-se hoje, inclusive, um retorno ao território tradicional (e reivindicação de demarcação de reservas) por parte de grupos tribais que foram removidos de suas terras para outras regiões, como é o caso dos Panará8 (nos estados de MT e PA), Katxuyâna ${ }^{9}$ (PA) e Kayabí10 (MT).

A respeito dos Panará, o ISA (2018) relata:

Os Panará, também conhecidos como Krenakore, foram oficialmente contatados em 1973, quando a estrada Cuiabá-Santarém estava em construção e cortava seu território tradicional na região do Rio Peixoto Azevedo. A violência do contato ocasionou morte de $2 / 3$ de sua população, em razão de doenças e massacres. À beira do extermínio, em 1975 foram transferidos pela Funai para o Parque Indígena do Xingu. Depois de 20 anos exilados, os Panará reconquistaram o que ainda havia de preservado em seu antigo território, onde construíram uma nova aldeia. Além dessa vitória, alcançaram um feito inédito na história dos povos indígenas e do indigenismo brasileiro, quando em 2000 ganharam nos tribunais, contra a União e a Funai, uma ação indenizatória pelos danos materiais e morais causados pelo contato. Tal vitória, se não lhes apaga as tristes marcas de sua história, projetam-lhes para um futuro mais digno (ISA, 2018, p.. 1) $)^{11}$.

Podemos observar, segundo relatado pelo ISA, o resgate do território pela comunidade indígena Panará, justamente no período histórico de emancipação do

\footnotetext{
${ }^{8}$ Povo indígena da família Jê (Área Cultural Tapajós/Madeira), também conhecido como Krenakore, presumivelmente, remanescente dos Kayapó do Sul, do período colonial.

${ }^{9}$ Povo indígena da família Karib (Área Cultural Norte-Amazônica).

${ }^{10}$ Povo indígena do tronco linguístico Tupi, família Tupi-Guarani (Área Cultural Tapajós/Madeira).

${ }^{11}$ Texto extraído do site: https://pib.socioambiental.org/pt/Povo:Panar\%C3\%A1. Publicado originalmente em 03/2004 e modificado pela última vez em 10/2019.
}

Geopauta, Vitória da Conquista; ISSN: 2594-5033, V. 5, n.1, 2021, e6504 
DEUS, J. A. S.; DIAS NETO, J.

multiculturalismo no Brasil, no final do século $X X$, logo após a redemocratização em 1988; que também obteve vitória em conflito judicial que envolveu o Estado brasileiro e a Fundação Nacionao do Índio (FUNAI), o que aliás, evidencia o já exposto antagonismo de interesses aqui abordado; o que não significa que a emergência do multiculturalismo tenha encerrado os conflitos entre povos indígenas e forças hegemônicas, mas, muito pelo contrário, tendo o redirecionado/lançado a uma outra instância e/ou patamar.

Nesse sentido, é possível identificarmos, também, um movimento de resgate de identidades de etnias que até recentemente eram consideradas extintas, pois, até então, se encontravam dissolvidas no interior da sociedade nacional; e que, após a ressignificação da questão indígena a partir do socioambientalismo e do multiculturalismo, emergiram, através das chamadas identidades emergentes, como é o caso dos Puruborá12, em Rondônia, que conforme o ISA:

Contatados oficialmente por Rondon no início do século XX no vale do rio Guaporé, os Puruborá foram, durante décadas, considerados extintos, misturados às muitas levas de seringueiros que ocuparam a região que futuramente viria a ser conhecida como Rondônia. Mas os Puruborá - o "povo que se transforma em onças"-, embora fragmentados e dispersos, lograram atravessar o século. E, em 2001, realizaram sua primeira assembleia, na qual reuniram os parentes espalhados por diversos lugares no estado de Rondônia e alhures, e reafirmaram sua luta pelo reconhecimento de seu território tradicional nas margens do rio Manoel Correia, luta que segue nos dias de hoje, como um dos povos definidos como "ressurgidos" ou "resistentes" na Amazônia brasileira (ISA, 2020, p.. 1) ${ }^{13}$.

E nesse contexto de resgate e ressurgimentos é que esse protagonismo assumido pelos grupos étnicos acaba por reverberar em outras situações, mas que, de igual forma, evidenciam como as comunidades indígenas brasileiras, a exemplo de outras culturas, como os quilombolas, têm buscado se articular, através da apropriação

\footnotetext{
${ }^{12}$ Povo indígena do tronco Tupi (Área Cultural Guaporé), contatado por Rondon, na Amazônia Meridional, no início do século XX.

${ }^{13}$ Texto extraído do site: https://pib.socioambiental.org/pt/Povo:Purubor\%C3\%A1. Publicado originalmente em 09/2015 e modificado pela última vez em 07/2018.
}

Geopauta, Vitória da Conquista; ISSN: 2594-5033, V. 5, n.1, 2021, e6504 
DEUS, J. A. S.; DIAS NETO, J.

dos códigos e dinâmicas da sociedade hegemônica, entre as quais é possível se destacar os seguintes fatos, que demostram a capilarização do protagonismo indígena em outras esferas sociais/culturais:

Quadro 1 - Compilado de casos que exemplificam o protagonismo em curso das comunidades indígenas no seio da sociedade multiculturalista ${ }^{14}$

\begin{tabular}{|c|c|c|}
\hline $\begin{array}{l}\text { ESFERA / } \\
\text { ÁREA }\end{array}$ & DESCRIÇÃO & FONTE \\
\hline Política & $\begin{array}{l}\text { Joênia Wapichana elege-se a } \\
\text { primeira deputada federal indígena } \\
\text { eleita, por Roraima, obtendo } 8.491 \\
\text { votos nas eleições de } 2018 \text {. }\end{array}$ & $\begin{array}{l}\text { Agência de notícias EBC Brasil } \\
\text { Link para acesso à matéria na íntegra: } \\
<\text { http://agenciabrasil.ebc.com.br/direitos- } \\
\text { humanos/noticia/2018-10/sou-resultado-do- } \\
\text { movimento-indigena-diz-1a-indigena-eleita- } \\
\text { deputada }> \\
\text { Acesso em } 05 \text { de dezembro de } 2018 .\end{array}$ \\
\hline Tecnologia & $\begin{array}{l}\text { Jovem Xavante cria canal no } \\
\text { YouTube e torna-se youtuber, com a } \\
\text { finalidade de combater } \text { o } \\
\text { preconceito conta os índios e } \\
\text { divulgar informações sobre a } \\
\text { cultura indígena. }\end{array}$ & $\begin{array}{l}\text { Portal BBC News Brasil } \\
\text { Link para acesso à matéria na íntegra: } \\
<\text { https://www.bbc.com/portuguese/brasil- } \\
\underline{46427800 ? \text { fbclid=IwAR1pq wHPYTOeIekzYkIrq3 }} \\
\text { vN0njQ-07aNeTudov9b6hZ-MvJNjoUpSPQS4> } \\
\text { Acesso em 05 de dezembro de } 2018 .\end{array}$ \\
\hline Economia & $\begin{array}{l}\text { Índios Yanomami descobrem } \\
\text { espécie de cacau especial, chamado } \\
\text { de 'fruta dourada', para fazer } \\
\text { chocolates finos. }\end{array}$ & $\begin{array}{l}\text { Portal BBC News Brasil } \\
\text { Link para acesso à matéria na íntegra: } \\
<\underline{\text { https://www.bbc.com/portuguese/brasil- }} \\
\underline{46226323}> \\
\text { Acesso em } 05 \text { de dezembro de } 2018 .\end{array}$ \\
\hline Social & $\begin{array}{l}\text { Mapulu Kamayurá, cacica e pajé do } \\
\text { Alto Xingu, recebe Prêmio de } \\
\text { Direitos Humanos 2018, do } \\
\text { Ministério de Direitos Humanos do } \\
\text { Brasil }\end{array}$ & $\begin{array}{l}\text { Portal da FUNAI } \\
\text { Link para acesso à matéria na íntegra: } \\
<\text { http://www.funai.gov.br/index.php/comunicaca } \\
\text { o/noticias/5117-mapulu-kamayura-cacica-e-paje- } \\
\text { do-alto-xingu-recebe-premio-de-direitos- } \\
\text { humanos-2018> } \\
\text { Acesso em } 05 \text { de dezembro de } 2018 .\end{array}$ \\
\hline Educação & $\begin{array}{l}\text { Vestibular indígena da UNICAMP } \\
\text { é realizado em São Gabriel da } \\
\text { Cachoeira, município brasileiro } \\
\text { com o maior percentual de } \\
\text { população indígena do país, onde } \\
90,0 \% \text { dos habitantes pertencem a } \\
23 \text { etnias na região do Rio Negro. }\end{array}$ & $\begin{array}{l}\text { Portal do ISA } \\
\text { Link para acesso à matéria na íntegra: } \\
<\text { http://www.funai.gov.br/index.php/comunicaca } \\
\text { o/noticias/5117-mapulu-kamayura-cacica-e-paje- } \\
\underline{\text { do-alto-xingu-recebe-premio-de-direitos- }} \\
\text { humanos-2018> } \\
\text { Acesso em } 06 \text { de dezembro de } 2018 .\end{array}$ \\
\hline $\begin{array}{l}\text { Economia / } \\
\text { Meio } \\
\text { Ambiente }\end{array}$ & $\begin{array}{l}\text { Empresários e povos indígenas } \\
\text { discutem alternativas para energia } \\
\text { limpa em Roraima. }\end{array}$ & $\begin{array}{l}\text { Portal do ISA } \\
\text { Link para acesso à matéria na íntegra: } \\
<\text { https://www.socioambiental.org/pt-br/blog/blog- } \\
\text { do-rio-negro/empresarios-e-povos-indigenas- }\end{array}$ \\
\hline
\end{tabular}

\footnotetext{
${ }^{14}$ Este quadro retoma situações envolvendo a atuação indígena ou em prol dela, obviamente que sem pretender esgotar o universo desses casos, haja vista o seu elevado quantitativo e a intensidade/dinamicidade com que acontecem na atualidade. Em suma, o propósito é justamente explicitar o protagonismo indígena em curso e suas ramificações em diferentes setores da sociedade.
}

Geopauta, Vitória da Conquista; ISSN: 2594-5033, V. 5, n.1, 2021, e6504 
DEUS, J. A. S.; DIAS NETO, J.

\begin{tabular}{|c|c|c|}
\hline & & $\begin{array}{l}\text { discutem-alternativas-para-energia-limpa-em- } \\
\text { roraima }> \\
\text { Acesso em } 06 \text { de dezembro de } 2018 .\end{array}$ \\
\hline $\begin{array}{l}\text { Meio } \\
\text { Ambiente }\end{array}$ & $\begin{array}{l}\text { Comissão Interamericana de } \\
\text { Direitos Humanos pede reparação } \\
\text { aos impactados por Belo Monte. }\end{array}$ & $\begin{array}{l}\text { Portal do ISA } \\
\text { Link para acesso à matéria na íntegra: } \\
<\text { https://www.socioambiental.org/pt-br/blog/blog- } \\
\text { do-xingu/comissao-interamericana-de-direitos- } \\
\text { humanos-pede-reparacao-aos-impactados-por- } \\
\text { belo-monte }> \\
\text { Acesso em } 06 \text { de dezembro de } 2018 .\end{array}$ \\
\hline $\begin{array}{l}\text { Comunicaçã } \\
\text { o }\end{array}$ & $\begin{array}{l}\text { No noroeste amazônico, indígenas } \\
\text { realizam comunicação por direitos. }\end{array}$ & $\begin{array}{l}\text { Portal do ISA } \\
\text { Link para acesso à matéria na íntegra: } \\
<\underline{\text { https://www.socioambiental.org/pt-br/blog/blog- }} \\
\text { do-rio-negro/no-noroeste-amazonico-indigenas- } \\
\text { realizam-comunicacao-por-direitos }> \\
\text { Acesso em } 06 \text { de dezembro de } 2018 .\end{array}$ \\
\hline
\end{tabular}

Elaboração: DIAS NETO (2018).

A título de exemplo, o Quadro 2 apresenta casos recentes que envolveram a atuação de indígenas ou de instituições que militam em função da causa indígena no Brasil. Em síntese, o que observamos é que há um processo em curso de maior protagonismo por parte das comunidades indígenas e que desafia o status quo com base no próprio aparato institucional que o sustenta, em um movimento dialético cujos desdobramentos não são possíveis de se antecipar. Os grupos étnicos, assim, ocupam espaços, se articulam, ganham notoriedade e visibilidade, se (re)inventam, apropriam-se de códigos, enfim, valem-se de estratégias para sobreviver no curso das transformações da sociedade global capitalista e, em meio ao caos, tentam sublinhar suas especificidades culturais com a intenção de garanti-las.

E o que devemos ter em mente é que, embora o multiculturalismo tenha promovido um contexto favorável à atuação dos grupos étnicos, ele não foi capaz de encerrar o conflito que envolve a questão indígena, embora, conforme já demarcado, o tenha remetido a outra esfera, a jurídico-normativa. Emergem, assim, novos desafios no que diz respeito à sua efetivação em termos práticos, apesar de termos observado, através dos casos relatados, que as comunidades indígenas têm se articulado e atuado de forma destacada nas distintas esferas da sociedade contemporânea.

\section{Considerações Finais}

Geopauta, Vitória da Conquista; ISSN: 2594-5033, V. 5, n.1, 2021, e6504 
DEUS, J. A. S.; DIAS NETO, J.

O paradigma multiculturalista, influenciado pelo socioambientalismo emergente e pela ampliação do alcance dos mass media, em um contexto que Amorim Filho (1999) classificou por "novo ambientalismo", conforme já abordado neste artigo, contribuiu para que fosse lançado um novo olhar sobre a questão cultural, que foi ressignificada e (re)valorizada a partir dessa conjuntura, em certa medida favorável, à atuação dos grupos étnicos e dos movimentos sociais que possuem como pauta a defesa da diversidade sociocultural, sem aqui nos abster de considerar, em uma perspectiva crítica, os novos desafios decorrentes desse período, por exemplo, marcado pela institucionalização dos conflitos entre poder hegemônico e grupos minoritários, como acontece nos processos de licenciamento ambiental.

Com base nas reflexões apresentadas, é possível ponderarmos, portanto, acerca da importância dos paradigmas do socioambientalismo e do multiculturalismo para a configuração da (des)organização sociogeográfica contemporânea, sobretudo, no que diz respeito às possibilidades de articulação e atuação políticas dos grupos étnicos, com destaque para as comunidades indígenas, que de forma autêntica tem se apropriado destes códigos para reivindicarem seus direitos. Nesse processo, a emergência da cultura através dos movimentos étnicos, muitos deles motivados por conflitos territoriais, oportunizaram às comunidades tradicionais assumirem maior protagonismo no cenário nacional e internacional, pois, o paradigma multiculturalista forneceu as bases para a emergência de um contexto favorável ao desenvolvimento e vocalização dos movimentos culturais que, consequentemente, fomentaram e ampliaram os estudos culturais, cada vez mais valorizados, inclusive no interior da própria Geografia.

E esses processos são apropriados pela ciência geográfica, que se encarrega de refletir a respeito dos modos de configuração de novos territórios, retorno às territorialidades, arranjos sócio-espaciais, lutas pela apropriação do espaço geográfico, experiência dos sujeitos nos lugares, etc., de forma autêntica e original, aspecto que 
DEUS, J. A. S.; DIAS NETO, J.

impulsiona a Geografia Cultural e faz dela, atualmente, uma das áreas de maior dinamicidade no interior da Geografia.

\section{Referências}

ACSELRAD, H.. Justiça ambiental - ação coletiva e estratégias argumentativas. In: Conflitos ambientais no Brasil. Rio de Janeiro: Relume Dumará: Fundação Heinrich Boll, 2004. p. 7-12.

AMORIM FILHO, O. B.. Topofilia, Topofobia e Topocídio em Minas Gerais. In: DEL RIO, V.; OLIVEIRA, L.. Percepção Ambiental: A experiência brasileira. São Paulo: UFSCar/Studio Nobel, 1999, 2ª ed. p. 139-152.

BARBIERI, E.. Biodiversidade: capitalismo verde ou ecologia social? Editora Cidade Nova, 1998.

BASSO, J.. O direito às terras indígenas e o multiculturalismo como bases para a sustentabilidade. Revista de Estudos Sociais, v. 17, n. 34, 2015.

BULLARD, R. D.. A anatomia do racismo ambiental e o movimento por justiça ambiental. In: IBASE. Movimento Sindical e Defesa do Meio Ambiente: o debate internacional. Rio de Janeiro: Arte Maior, 2000, p. 32-41. Série Sindicalismo e Justiça Ambiental, vol. 3.

COGO, D.. Multiculturalismo, comunicação e interculturalidade: cenários e itinerários conceituais. In: PERUZZO, C. M. K.; PINHO, J. B.. Comunicação e Multiculturalismo. São Paulo: INTERCOM, Manaus: Universidade do Amazonas, 2001. p. 13-45.

COSTA, B. P.; NASCIMENTO, T. F.. Fenomenologia e geografia: teorias e reflexões. Geografia, Ensino \& Pesquisa, vol. 20, n.3, p. 43-50, 2016.

D'ADESKY, J.. Pluralismo étnico e multiculturalismo. Afro-Ásia, 19/20, 1997. p. 165182. Disponível in: <https://portalseer.ufba.br/index.php/afroasia/article/download/20952/13555> Acesso em 05 de abril de 2018.

DEUS, J. A. S.; CASTRO, H. M.. Um olhar etnogeográfico sobre as paisagens culturais barrocas do hinterland brasileiro na(s) minas oitocentista(s). XII EGAL (Encontro de Geógrafos da América Latina), 2009. Disponível in:

<http://observatoriogeograficoamericalatina.org.mx/egal12/Ensenanzadelageografia/In vestigacionydesarrolloeducativo/16.pdf $>$ Acesso em 05 de abril de 2018.

DEUS, J. A. S.. Paisagens Culturais Alternativas e Protagonismo Etnopolítico de Comunidades Tradicionais no Hinterland Brasileiro. In: TUBALDINI, M. A. S.;

Geopauta, Vitória da Conquista; ISSN: 2594-5033, V. 5, n.1, 2021, e6504 
DEUS, J. A. S.; DIAS NETO, J.

\section{GIANASI, L. M.. Agricultura Familiar, Cultura Camponesa e Novas}

Territorialidades no Vale do Jequitinhonha: Gênero, Biodiversidade, Patrimônio Rural, Artesanato e Agroecologia. Belo Horizonte: Fino Traço Editora, 2012, p. 35-50.

DIAS NETO, J.. Aqui e Lá: Olhares e fronteiras entre a comunidade indígena Pataxó e a sociedade envolvente no município de Carmésia/MG. Dissertação de mestrado apresentada ao Programa de Pós-Graduação em Geografia da Universidade Federal de Minas Gerais/Instituto de Geociências (IGC), 2019. 334 p.

DIAS, G. V.; TOSTES, J. G. R.. Desenvolvimento sustentável: do ecodesenvolvimento ao capitalismo verde. Revista da Sociedade Brasileira de Geografia, v. 2, n. 2, p. 20072009, 2009. Disponível em:

$<$ https://www.researchgate.net/profile/Guilherme Dias14/publication/266485934 Dese nvolvimento sustentavel do ecodesenvolvimento ao capitalismo verde/links/595505 7c458515bbaa21e4da/Desenvolvimento-sustentavel-do-ecodesenvolvimento-aocapitalismo-verde.pdf $>$ Acesso em 04 de dezembro de 2018.

GOMES, A. K.. Direitos Humanos e Multiculturalismo. Revista Eletrônica da Faculdade de Direito de Franca, v. 3, n. 1, 2010. Disponível em:

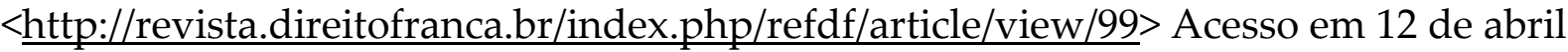
de 2018.

HOGAN, D.. População e Meio Ambiente. Textos NEPO 16. Núcleo de Estudos de População, Universidade Estadual de Campinas - UNICAMP, Campinas, São Paulo, 1989.

INSTITUTO SOCIOAMBIENTAL (ISA). Convenção 169 da OIT é instrumento para enfrentar violação de direitos. Disponível em: < https://www.socioambiental.org/ptbr/noticias-socioambientais/convencao-169-da-oit-e-instrumento-para-enfrentarviolacao-de-direitos> Acesso em 20 de setembro de 2017.

INSTITUTO SOCIOAMBIENTAL (ISA). Panará. Disponível em: $<$ https://pib.socioambiental.org/pt/Povo:Panar\%C3\%A1> Acesso em 04 de dezembro de 2018.

INSTITUTO SOCIOAMBIENTAL (ISA). Puruborá. Disponível em: $<$ https://pib.socioambiental.org/pt/Povo:Purubor\%C3\%A1> Acesso em 11 de abril de 2020.

IORIS, R. R.. Culturas em choque: a globalização e os desafios para a convivência multicultural. São Paulo: Annablume, 2007. 103 p.

OLIVEIRA, R. C.. Caminhos da identidade: ensaios sobre etnicidade e multiculturalismo. São Paulo: Editora UNESP, 2006. 258 p. 
PAULA, E. A.; MORAIS, M. J.. O conflito está no ar: povos da floresta e espoliação sob o capitalismo verde. Estudos de Sociologia, v. 18, n. 35, 2013. Disponível em: $<$ https://periodicos.fclar.unesp.br/estudos/article/view/6458> Acesso em $04 \mathrm{de}$ dezembro de 2018.

RIBEIRO, D.. Os índios e a civilização: a integração das populações indígenas no Brasil moderno. São Paulo: Companhia das Letras, 1996.

TORRES, C. A.. Introdução: as aventuras secretas da ordem. In: TORRES, C. A Democracia, Educação e Multiculturalismo: dilemas da cidadania em um mundo globalizado. Petrópolis: Editora Vozes, 2001. p. 13-20.

Contribuição dos autores: José Dias Neto: Elaboração, discussão dos resultados, pesquisa bibliográfica, revisão do texto José Antônio Souza de Deus : Supervisão, análise final dos resultados e revisão do texto 